medical complication of adolescent anorexia nervosa.

However, I am aware of many reports of serious complications such as irreversible failure of linear growth, irreversible failure of breast development, and cardiac abnormalities in this patient group. ${ }^{4}$ Again, the views of my colleagues treating younger patients would be appreciated.

Another interesting point raised by Dr Wrate is that with regard to young people with anorexia nervosa, risk may be 'socially constructed'. The implication is that if a risk is socially constructed rather than medically evidenced, it is related to the needs of individuals and systems such as the family and hospitals rather than a real risk of death. This may be true in many cases, especially if the usual risk factors are not too seriously impaired. However, I think it would be dangerous to apply it to the most seriously ill, for example a patient with a BMI of 10 .

Finally, there is the issue of patients resisting nasogastric feeding as opposed to treatment as such. This is a complicated matter. The act of admitting a patient to a specialist eating disorders unit may well engender fury in the patient and a determination not to gain weight. On the other hand, the admission may have been appropriate because of their dire physical state. In adult eating disorder services there is varying opinion about whether a seriously ill patient ever requires nasogastric feeding. If a patient resists eating, as may be the case, the option is to provide nutrition against their wishes, often under the Mental Health Act 1983. This might involve forcing the patient to eat by restraining them and pushing food into their mouth. This may be ineffective, or so aversive to staff that nasogastric feeding may be preferred. Some have said that skilled nursing can always result in a patient accepting food, thereby avoiding nasogastric feeding. I suspect that the situation in which a patient's life would be lost if forced feeding were not done is more commonly encountered in adults, as suggested by Dr Wrate. However, when it does occur, clinicians may be forced into more and more coercive treatment. Occasionally, such treatment may not be short lived and there are, at present, several adult patients in units around the UK receiving forced nutrition, under the Mental Health Act, by nasogastric or percutaneous endoscopic gastrostomy (PEG) feeds for periods which can run to several years. This may be very aversive to patients, staff and relatives, not to mention the enormous cost to the National Health Service ( $\notin 1000$ per day is not unusual in this situation), and merits audit and research.

1 Royal College of Psychiatrists, Royal College of Physicians. MARSIPAN: Management of Really Sick Patients with Anorexia Nervosa: Report from the MARSIPAN Group (College Report CR162). Royal College of Psychiatrists, 2010

2 Royal College of Psychiatrists. Junior MARSIPAN: Management of Really Sick Patients under 18 with Anorexia Nervosa: Report from the Junior MARSIPAN Group (College Report CR168). Royal College of Psychiatrists, 2012

3 Rosling AM, Sparén P, Norring C, von Knorring A-L. Mortality of eating disorders: a follow up study of treatment in a specialist unit 1974-2000. Int J Eat Disord 2011; 44: 304-10.

4 Katzman DK. Medical complications in adolescents with anorexia nervosa: a review of the literature. Int J Eat Disord 2005; 37 (suppl): S52-9; S87-9.

Paul Robinson Research Consultant Psychiatrist, Barnet Enfield and Haringey Mental Health NHS Trust, London N15 3TH, UK, email: paul.robinson@beh-mht.nhs.uk

doi: $10.1192 / \mathrm{pb} .36 .8 .317$

\section{From Rabone to reality}

Large et al draw valuable attention to the flawed information on which the Supreme Court based its decision to uphold the appeal of Rabone against the Pennine Care NHS Foundation Trust, ${ }^{2}$ identifying a number of well-recognised biases that prompted the judges to overvalue the risk of suicide by a factor of 40 .

Another significant bias that is often overlooked in posthoc analyses of serious untoward events concerns the value framework of the assessor, described with precision by Kahneman \& Tversky. ${ }^{3}$ Expert witnesses, although owing a primary duty to provide valid information to the court, are nevertheless instructed by legal professionals who are obliged to adopt either a defensive or offensive stance given the inherently adversarial nature of the legal system. The differing value frameworks that this provides are evident in the discrepancy in the evaluations of the 'immediate risk' posed by Ms Rabone of between $70 \%$ (as estimated by the claimants) and $20 \%$ (as estimated by the defendants). That such a spectacular discrepancy might point to the meaninglessness of a numerical approach seems to have escaped consideration.

Instead, deferring to the expert status of the witnesses, the Court appears to have dealt with this variance by taking the most conservative figure as the valid baseline for their consideration.

The judgments derived from such flawed considerations do little to help those who daily face the difficult task of attempting to 'second guess' (i.e. to anticipate) the intentions and behaviours of a mind disturbed by what the Court termed 'a recurrent depressive disorder'.

Most mental health professionals appear to agree that a sincere wish to die is one of the less common reasons for the issue of a suicidal threat. ${ }^{4}$ Unless such considerations are taken into account by those who define the laws by which our best practices are shaped and defined, misinformed legalism will continue to exert an increasingly demoralising effect on those who do their best in a very difficult situation.

The present judgment will, in all likelihood, lead to an increase in the detention of individuals with depression against their wishes in services that, especially in the current social and economic climate, may not be as well equipped to reduce risk (in either the short or long term) as either judges or the general public may like to think. Practical measures derived from ethics and common sense may be of more help here than actuarial procedures.

Ms Rabone appeared to had given a clear commitment not to self-harm at the time of her departure. It is unclear how much weight was given to this fact by the Court, but it presumably carried considerable weight in the mind of the unfortunate psychiatrist who granted her informal leave. A useful standard by which to judge the wisdom of such a decision might involve contemporary recording of unequivocal evidence of future orientation. At its simplest, this could comprise clear recording of the patient's agreement not to act on impulses of self-harm, accepted as valid regardless of the private discomfort of those involved, alongside an equally clear recording of the patient's agreement to return to care at a clearly agreed place and point in time. All individuals failing these tests should be subject to consideration for legal detention. 
To this, a prudent psychiatrist might add a written note setting out the grounds for his or her decision, relating the individual circumstances of the case at hand. Such an entry in the case notes made at every significant point during the patient's progress would be time consuming and might read, in effect, as an open letter to a future court, but its use would seem to be the most appropriate response to the judgment handed down by the Supreme Court on this occasion.

1 Large M, Ryan CJ, Callaghan S. Hindsight bias and the overestimation of suicide risk in expert testimony. Psychiatrist 2012; 36: 236-7.
2 Rabone v. Pennine Care NHS Foundation Trust [2012] UKSC 2.

3 Kahneman D, Tversky A. Choices, values and frames. Am Psychol 1984; 39: 341-50.

4 Salter M, Turner T. Community Mental Health Care: A Practical Guide to Outdoor Psychiatry: 203-24. Churchill Livingstone, 2008.

Mark Salter, consultant psychiatrist, East London NHS Foundation Trust, email: mark.salter@eastlondon.nhs.uk

doi: $10.1192 / p b .36 .8 .318$ 